\title{
A STUDY ON PRESSURE SURGE ACCOMPANIED BY REPEATED VALVE OPERATION IN OIL HYDRAULIC PIPELINE
}

\author{
Ill-Yeong Lee*, Yong-gil Jung** \\ Man-Oh Yum***, Jin-Kul Lee**** \\ *Dept. of Marine Engineering, National Fisheries University of Busan \\ Busan, Korea \\ **Dept. of Marine Engineering, Tong-Yeong Fisheries Junior College \\ Kyungnam, Korea \\ ***Dept. of Mechanical Engineering, Kyungnam University \\ Kyunganm, Korea \\ ****Dept. of Mechanical Engineering, Busan University \\ Busan, Korea
}

\begin{abstract}
In a large scale oil hydraulic system having repeatedly operated actuator, such as a large scale forging press, pressure surges often occur due to the recombination of oil column in a return line attached to the downstream side of a directional control valve. Especially, the pressure surges appear very severe ones at a certain valve operating frequency. These pressure surges restrict the operating frequency $0=$ the hydraulic system. But there are few reports about the above mentioned phenomenon.

In this study, therefore, the authors investigate the exact reason why such severe pressure surges occur at a certain range of valve operating frequency. And for that purpose, the relationship between pressure surges and valve operating frequency is studied by e $\because$ periments and numerical computations.
\end{abstract}

KEYWORDS

Hydraulic Power system, Surge Pressure, Transient Flow, Repeatedly Operated Valve

TOMENCLATURE

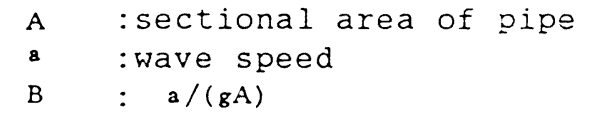

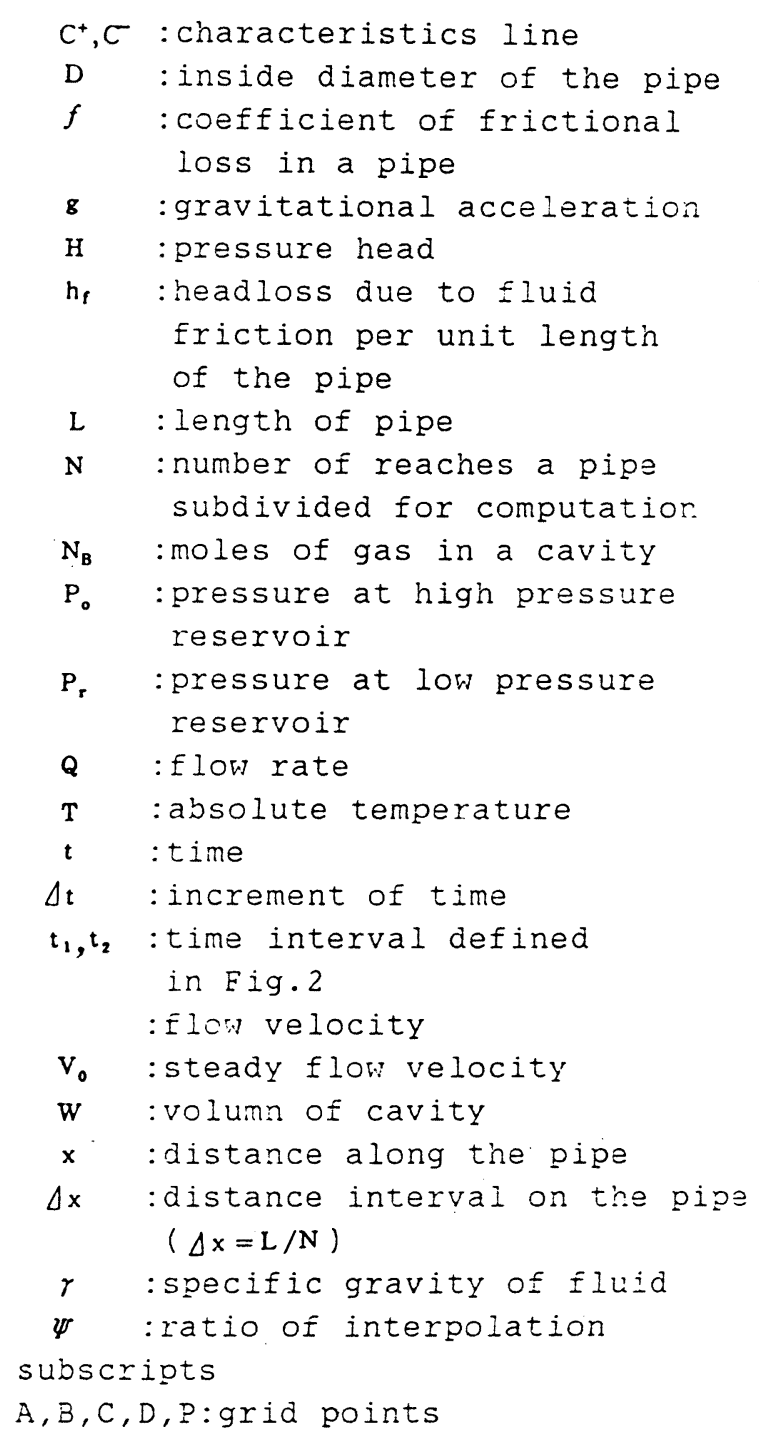




\section{INTRODUCTION}

In a large scale oil hydraulic system having repeatedly operated actuator, such as a large scale forging press, severe pressure surges often occur due to the recombination of oil column separated in the return line attached to the downstream side of a directional control valve. Especially when the valve operation frequency exceeds a certain limit the pressure surges apear more significant ones with a crushing sound. So, in a large scale oil hydraulic system as a large free forging press the operation frequency of the directional control valve is generally set to a certain low values which is decided from field engineers' experiences. Nevertheless the generation mechanism of the pressure surges is not yet clarified.

And also, it is known by field engineers' informations and authors' preparatory experiment that the pressure surges are influenced very much by the variation of valve operation frequency. Therefore, the authors investigate the relationship between the valve operation frequency and the pressure surges by experiment and numerical computation. The object of experimental pipeline is a model pipeline simplifies a return line of a large scale forging press. By consideration of experimental results and computation results, we try to explain more rationaliy the generation mechanism of the surge pressure.

EXPERIMENTAL APPARATUS AND EXPERIMENTAL PROCEDURE

Fig.1 shows a simplified pipe model of a return line of a large scale oil hydraulic forging press. Experiment in this study applies to the pipe model which has simple boundary conditions and smaller dimensions compared to a real equipment but can simiiarly describe physical aspects of the real equipment. Schemetic diagram of the experimental apparatus is shown in Fig.2. Accumulators are used as constant pressure reservoirs, and pressure setting is done with relief valves. The pipe used in experiment is copper pipe which has $12.7 \mathrm{~mm}$ in inside diameter and $25 \mathrm{~m}$ in total length. A directional control valve is installed at a distance of $5 \mathrm{~m}$ from the upstream end of the pipe. The pressure variations are measured using strain gauge type pressure transducers set at the positions of $5 \mathrm{~m}$ and $15 \mathrm{~m}$ from the upstream end of the pipeline. A commercial hydraulic oil is used, and the kinematic viscosity and specific gravity of it are $45.5 \mathrm{cSt}$ at $45^{\circ} \mathrm{C}$ and 0.866 at $25^{\circ} \mathrm{C}$ respectively. The directional control valve employed is a double acting solenoid spring offset type, which can operate repeatedly according to the timing as shown in Fig. 3. For this purpose, the authors specially designed and made a valve controller which generated periodic on-off control signals with arbitary duration time.

The experiment is started under steady flow state which is established by opening the valve fully and setting the pressure at both accumulators. The experiment is carried out by operating the vaive

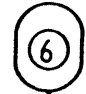

(2)

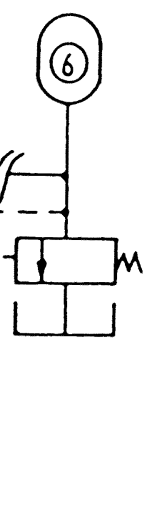

(1)

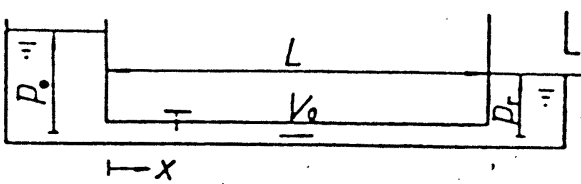

Fig.1 Pipe model for experiment and computation

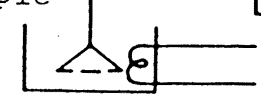

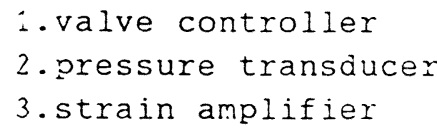

Fig. 2 Schematic diagram of experimental apparatus
4. memoryscope

5.X-Y PIこたニき

6. accumuiazon 


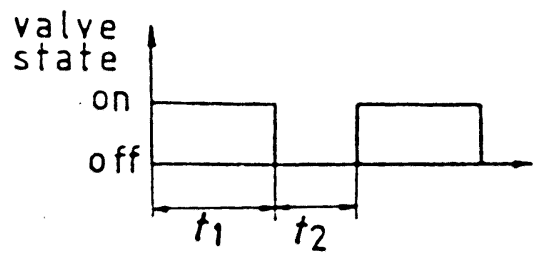

Fig. 3 Valve operating state

using the valve controller. The pressure variations are recorded on a $X-Y$ plotter through a duaichannel memoryscope. Also, the duration time at opened and closed state of the valve are measured on the pressure records.

\section{NUMERICAL ANALYSIS}

The equations of motion and continuity for one-dimensional Eiow in horizontal pipe are given as follows.

$$
\begin{aligned}
& \frac{\partial \mathrm{V}}{\partial t}+\mathrm{V} \frac{\partial \mathrm{V}}{\partial x}+\mathrm{g} \frac{\partial \mathrm{H}}{\partial x}+\mathrm{g} \cdot \mathrm{h}_{\mathrm{f}}=0 \\
& \frac{\partial \mathrm{H}}{\partial t}+\mathrm{V} \frac{\partial \mathrm{H}}{\partial x}+\frac{\mathrm{a}^{2}}{\mathrm{~g}} \frac{\partial \mathrm{V}}{\partial x}=0
\end{aligned}
$$

Thsee equations can be transformed into a pair of total differential equations by characteristics method. Anci if taking the difference on characteristics lines $C^{+}$ and $\mathrm{C}^{-}$, we get the following finite differene equations.

$$
\begin{aligned}
& C^{+}: H_{P}=C_{P}-B \cdot Q_{P} \\
& C^{-}: H_{P}=C_{M}+B \cdot Q_{P}
\end{aligned}
$$

where

$$
\begin{aligned}
& C_{P}=H_{A}+B \cdot Q_{A}-h_{f} \\
& C_{M}=H_{B}-B \cdot Q_{B}+h_{f}
\end{aligned}
$$

Since the flo: pattern in the experiment is laminar, the headloss per unit length of a pipe is computed considering the effects of frequency dependent friction in unsteady laminar flow.( 1 ) Also, the volume of the cavity during liquid column separation is computed by the gas discrete model( $(2)$. The boundary condition of the directional control valve is shown in $\Xi i g .4$. During the valve operating, the flow rate across the valve is described as following equation.

$$
\begin{gathered}
Q_{P_{1}}=Q_{P_{2}}=\operatorname{sign}\left(C_{P_{1}}-C_{N_{2}}\right) \frac{Q_{0}}{\sqrt{\Delta H_{0}}} \\
\sqrt{\left|H_{P_{1}}-H_{P_{2}}\right|}
\end{gathered}
$$

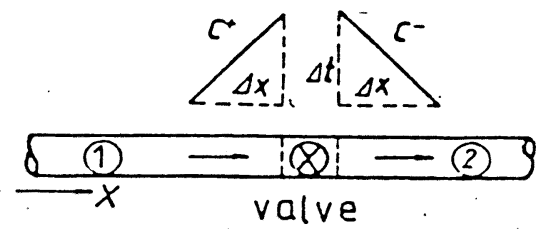

Fig.4 Boundary condition of the directional control value

Where, $H_{0}$ and $l_{0}$ are steady head loss and steady flow rate across the valve at fully open valve state, and subscripts 1.2 indicate the upstream and downstream pipe. So, pressure head and flow rate just after the valve can be computed by solving eqution (3), (4) and (5) simultaneously.

\section{EXPERIMENTAL RESULTS AND DISCUSSIONS}

Fig.5 illustrates the records of the pressure waves taken just after the directional valve $(x=5 \mathrm{~m})$. Fig.5. is is the case that $t_{2}$ is comparatively long, and $t_{1}$ is longer than $t_{2}$, where $t_{1}$ and $t_{2}$ is defined in Fig.3. Fig.5.(2). 3 and 娄 are the case that $t \geqslant$ is gradually shortened under the same physical conditions with Fig.5. 0 .

Fig. 5 shows that pressure surges occur according to the oil column recombination, and in certain operation frequency the pressure surges appear very severe cnes with crushing noise. Fig.5. is one example of such cases. From these experimental results, it is said that the magnitude of pressure surge becomes very big one when the raive opens during the duration of cavity. Fig.5. (5) the case that $t_{1}$ is adjusted to approximately equivalent value with $t_{2}$. Fig.5. (5) shows that the pressure waves have comparatively good reproducibility. Also, it is known that the computed results from characteristics method show good agreements with experimental results.

How, comparing Fig.5. (3) with Eig.5., it is said that very severe pressure surges appear at Fig.5.S although the valves open during the duration of cavity at both cases. So, in order to investigate the reason for the 


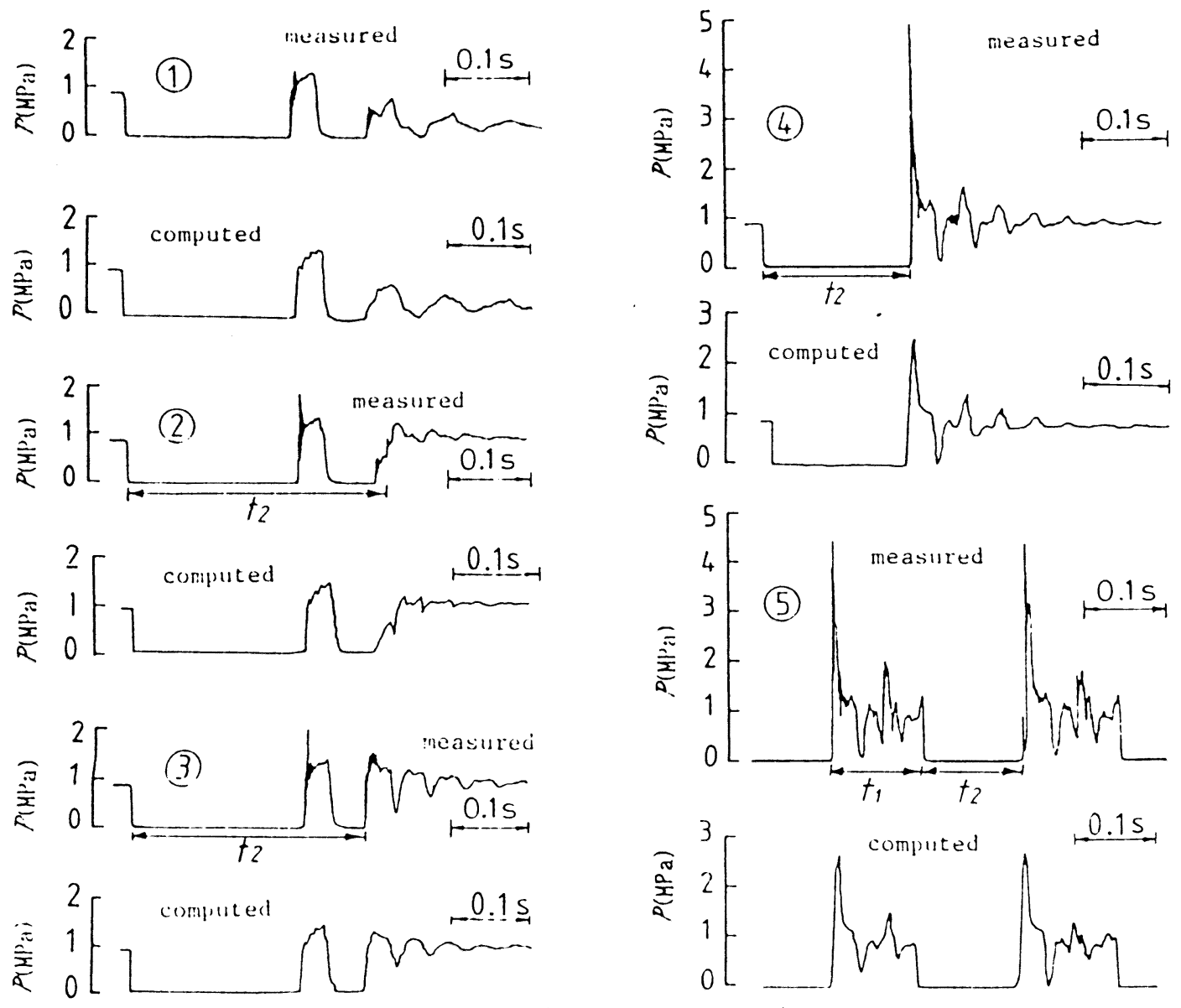

Fig. 5 Comparision of experimental results with computed results $\left(P_{0}=1.15 \mathrm{MPa}\right.$ abs, $P_{z}=0.3 \mathrm{MPa}$ abs, $\left.V_{0}=2.12 \mathrm{~m} / \mathrm{s}, x=5 \mathrm{~m}\right)$.
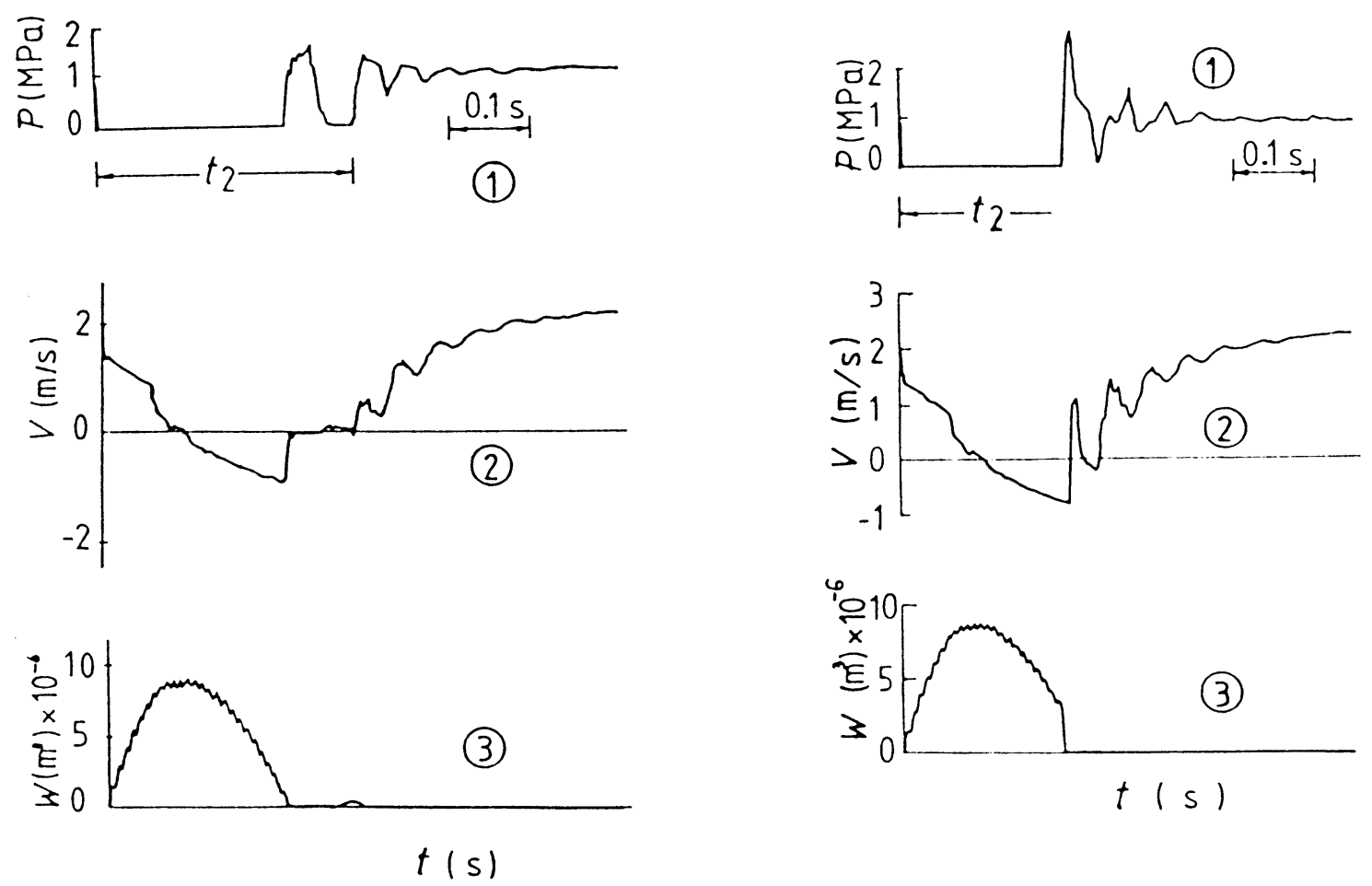

Fig. 6 Computed values of pressure (1), mean velocity(2) and cavity volume (3)

(the same physical conditions with Fig.5(a) (3), $x=5 \mathrm{~m}$ ) 
difference, we consider about the computed results of the variation of pressure, mean velocity and cavity volume shown in Fig. 6 . Fig.6(a), (b) is obtained at the same physical conditions with Fig.5. (3), (4) respectively. From Fig.6, it is explained clearly that the pressure surges are affected considerally by the variation rate of cavity volume and mean velocity.

\section{CONCLUSIONS}

The mechanism of the generation of severe pressure surge in the pipeline with repeatedly operated valve in a large scale oil hydraulic equipment was investigated experimentally and numerically, using a simplified pipe model. severe pressure surges were observed when the repeatedly operated valve opened before the first recombination of the cavity. The mechanism of severe pressure surge was explained rationally by consideration on the variation rate of pressure, mean velocity and cavity volume. And the surge pressure could be predicted with good agreement by computation with the method of characteristics.

\section{ACKNOWLEDGEMENTS}

The authors wish to thaink the Korean Learning Promotion Foundations under whose financial support this study was made.

\section{REFERENCES}

(1) Kagawa, T., et al., "High speed and Accurate Computing Method of Frequency-Dependent Friction in Laminar Pipe Flow for Characteristics Method", Trans. of Japan Soc. Mech. Engrs. (in Japanese), Vol. 49, No. 447 B (1983), p.2638.

(2) Wylie, E. B., "Simulation of Vaporous and Gaseous Cavitation" Trans. of ASME, Journal of Fluids engineering, Vol. 106 (1984). 